Copyright (C) 2014 by Academic Publishing House Researcher

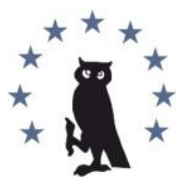

Published in the Russian Federation

European Journal of Medicine

Has been issued since 2013 .

ISSN: 2308-6513

E-ISSN: 2310-3434

Vol. 5, No. 3, pp. 144-148, 2014

DOI: $10.13187 /$ ejm.2014.5.144

www.ejournal5.com

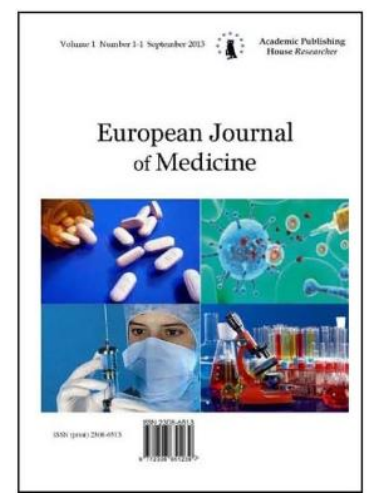

UDC 616.151.5 - 056. 7-07:618.3: 575.2

\title{
The Control Level of Bronchial Asthma in Dependence of Genotype by BCL1 Polymorphism of Glucocorticoids Receptor Gene and Body Mass Index
}

\author{
${ }^{1}$ Vladyslava V. Kmyta \\ ${ }^{2}$ Viktor F. Orlovskyi \\ 3 Lyudmyla N. Prystupa
}

\begin{abstract}
${ }^{1}$ Sumy State University, Ukraine
Department of internal medicine with postgraduate education 40022 Sumy, Troicka str., 48

Postgraduate student

E-mail: vlady_dytko@ukr.net

${ }^{2}$ Sumy State University, Ukraine 40022 Sumy, Pryvokzalna str., $3 \mathrm{a}$

$\mathrm{MD}, \mathrm{PhD}$, Professor

E-mail: Simmed50@gmail.com

3 Sumy State University, Ukraine

Department of internal medicine with postgraduate education

40022 Sumy, Troicka str., 48

$\mathrm{MD}, \mathrm{PhD}$, Professor

E-mail: Lyudmyla_prystupa@ukr.net
\end{abstract}

Family medicine department with course of propedeutics of internal medicine and endocrinology

\section{Abstract}

The frequency of allelic genotypes by BclI polymorphism glucocorticoids receptor gene (GR) had been studied in dependence of the control level of bronchial asthma (BA) and body mass index (BMI), and also- connection between those indicators.

188 patient with BA and 95 almost healthy humans were investigated. Determination of single nucleotide BclI polymorphism GR gene performed by the method of polymerase chain reaction with following analyze of the length of restriction fragments.

Our studies demonstrated connection between BA control, BclI polymorphism GR gene and BMI. Proved, that distribution $\mathrm{C} / \mathrm{C}, \mathrm{C} / \mathrm{G}$ and $\mathrm{G} / \mathrm{G}$ genotypes by BclI polymorphism in patients with BA showed reliable difference between patients with different BMI and connection G/G genotype with obesity. The reliable difference in distributing of genotype in dependence of BA control level has been proved: with controlled BA reliably often met C/C genotype, without control - G/G genotype. Therefore, proved, that frequency G/G genotype by BclI polymorphism GR gene in patients with BA with obesity and absence of control for the flowing of disease is reliably higher, that confirmed the role of this genotype, likewise, in obesity occurrence, so in absence of the control of disease.

Keywords: bronchial asthma; BclI polymorphism; body mass index; control. 


\section{Введение}

Известно, что ожирение негативно влияет на клиническое течение бронхиальной астмы (БА), причем масса тела связана дозозависимым образом с симптомами БА $[2,5]$. В исследованиях доказана связь между степенью тяжести БА и индексом массы тела (ИМТ) $[1,6]$, а также увеличение тяжести БА на 0,183 по шкале оценки с ростом ИМТ на каждый

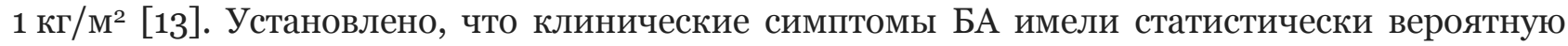
связь с ожирением [6]. Средний показатель уровня сложности контроля БА был почти вдвое выше у больных с ожирением по сравнению с пациентами, которые имели нормальную массу тела (НМТ). Исследования подтвердили наличие у тучных пациентов с БА более низкого ответа на ингаляционные глюкокортикоиды (иГКС) [9], а также - на комбинированные препараты, содержащие в своем составе иГКС и пролонгированные $\beta_{2^{-}}$ агонисты [3]. Это подтверждено более высокой применяемой дозой иГКС, более частыми приступами в ночное время и приемами $\beta_{2}$-агонистов, а также - высокой частотой и тяжестью обострений [3]. В связи с этим особое клиническое значение приобретает резистентность пациентов с ожирением к базисной терапии БА. Таким образом, ожирение способствует не только возникновению БА, а и утяжеляет ее течение - приводит к отдельному фенотипу заболевания, снижению эффективности лечения, хотя ассоциированные патогенетические механизмы при БА и ожирении нуждаются в углубленных дальнейших исследованиях. Решение данной проблемы может быть реализовано путем изучения метаболической патологии при ожирении, дальнейшей разработки концепции БА и ожирения как хронических заболеваний, сопровождающихся персистирующим воспалением, а также - поиска их общих генетических детерминант. Учитывая то, что исследовано плейотропные гены, ассоциированные с БА и ожирением, и данные отдельных исследований, доказывающих роль BclI полиморфизма гена глюкокортикоидных рецепторов (ГР) в возникновении висцерального ожирения [12], БА [8] и отсутствие данных о плейотропных эффектах у больных БА данного полиморфизма, целью исследования было изучение частоты аллельных генотипов по bcl1 полиморфизму гена ГР в зависимости от уровня контроля БА и массы тела, а также - вероятной взаимосвязи между данными показателями.

\section{Материал и методы исследования}

Обследовано 188 пациентов с БА. Контрольную группу составили 95 практически здоровых лиц взрослого возраста, не имевших в анамнезе БА и симптомов других аллергических заболеваний у себя и близких родственников. Уровень контроля БА оценивали согласно рекомендациям GINA (2011), а ИМТ - согласно рекомендациям ВОЗ.

Определение аллельного Bcl1 (rs41423247) полиморфизма 2-го экзона гена ГР проводили методом полимеразной цепной реакции с последующим анализом длины рестрикционных фрагментов по Fleury I. et al. с модификациями (2003). Статистическую обработку результатов проводили с использованием программы SPSS-17.

\section{Результаты исследования}

Установлено достоверное отличие в распределении генотипов по bcl1 полиморфизму гена ГР в зависимости от ИМТ по $\chi^{2}$ критерию Пирсона $\left(\chi^{2}=45,6, \mathrm{p}=0,001\right)$. Так, при наличии нормальной массы тела (НМТ) распределение генотипов по исследуемому полиморфизму было таким: C/C - 28,4\%, C/G - 57,9\%, a G/G - 13,7\%. При избыточной массе тела установлено такую частоту генотипов: $\mathrm{C} / \mathrm{C}, \mathrm{C} / \mathrm{G}$ и $\mathrm{G} / \mathrm{G}-31 \%, 31$ \% и $37,9 \%$, а ожирении $10,9 \%, 25 \%$ и $64,1 \%$.

Анализ распределения генотипов по BclI полиморфизму гена ГР в зависимости от степени контроля БА представлен в табл. 1. Установлено достоверное различие по $\chi^{2}$ критерию Пирсона (p=0,001) по распределению генотипов в зависимости от уровня контроля БА. Выявлено, что при наличии контролируемой БА достоверно чаще встречался генотип $\mathrm{C} / \mathrm{C}$, при наличии частичного контроля - генотип $\mathrm{C} / \mathrm{G}$, неконтролируемое течение ассоциировано с генотипом G/G по исследуемому полиморфизму. Детальный анализ распределения генотипов по BclI полиморфизму гена ГР у больных БА в зависимости от ИМТ и уровня контроля заболевания приведены в табл. 2, 3, 4. 
Частота генотипов по Всl1 полиморфизму гена ГР в зависимости от уровня контроля

\begin{tabular}{|c|c|c|c|c|c|c|}
\hline \multirow[t]{3}{*}{ Степень контроля } & \multicolumn{6}{|c|}{ Генотипы } \\
\hline & \multicolumn{2}{|c|}{$\mathrm{C} / \mathrm{C}$} & \multicolumn{2}{|c|}{$\mathrm{C} / \mathrm{G}$} & \multicolumn{2}{|c|}{$\mathrm{G} / \mathrm{G}$} \\
\hline & Абс. & $\%$ & Абс. & $\%$ & Абс. & $\%$ \\
\hline Контролированная & 12 & 75 & O & o & 4 & 25 \\
\hline $\begin{array}{l}\text { Частично } \\
\text { контролированная }\end{array}$ & 24 & 18,6 & 68 & 52,7 & 37 & 28,7 \\
\hline Неконтролированная & 7 & 16,3 & 12 & 27,9 & 24 & 55,8 \\
\hline
\end{tabular}

Распределение генотипов по Всl1 полиморфизму гена ГР у пациентов

Таблица 2 с контролируемой БА в зависимости от ИМТ

\begin{tabular}{|l|l|l|l|l|l|l|}
\hline \multirow{2}{*}{ Генотипы } & \multicolumn{9}{|c|}{ ИМТ } \\
\cline { 2 - 8 } & \multicolumn{3}{|c|}{$\leq 24,9$} & \multicolumn{2}{c|}{$25-29,9$} & \multicolumn{2}{c|}{$30 \leq$} \\
\cline { 2 - 8 } & Абс. & $\%$ & Абс. & $\%$ & Абс. & $\%$ \\
\hline $\mathrm{C} / \mathrm{C}$ & 10 & 83,3 & 1 & 8,3 & 1 & 8,3 \\
\hline $\mathrm{G} / \mathrm{G}$ & $\mathrm{O}$ & $\mathrm{O}$ & 3 & 75 & 1 & 25 \\
\hline $\mathrm{X}^{2}=9,33 ; \mathrm{p}=0,009$ & \multicolumn{7}{|l|}{} \\
\hline
\end{tabular}

Таблица 3

Распределение генотипов по Всl1 полиморфизму гена ГР у пациентов с частично контролируемой БА в Зависимости от ИМТ

\begin{tabular}{|c|c|c|c|c|c|c|}
\hline \multirow[t]{3}{*}{ Генотипы } & \multicolumn{6}{|c|}{ ИМТ } \\
\hline & \multicolumn{2}{|c|}{$\leq 24,9$} & \multicolumn{2}{|c|}{$25-29,9$} & \multicolumn{2}{|c|}{$30 \leq$} \\
\hline & Абс. & $\%$ & Абс. & $\%$ & Абс. & $\%$ \\
\hline $\mathrm{C} / \mathrm{C}$ & 15 & 62,5 & 4 & 16,7 & 5 & 20,8 \\
\hline $\mathrm{C} / \mathrm{G}$ & 48 & 70,6 & 9 & 13,2 & 11 & 16,2 \\
\hline $\mathrm{G} / \mathrm{G}$ & 12 & 32,4 & 6 & 16,2 & 19 & 51,4 \\
\hline$\chi^{2}=17,7 ; p=$ & & & & & & \\
\hline
\end{tabular}

Таблица 4

Распределение генотипов по Bcl1 полиморфизму гена ГР у пациентов с неконтролируемой БА в зависимости от ИМТ

\begin{tabular}{|c|c|c|c|c|c|c|}
\hline \multirow[t]{3}{*}{ Генотипы } & \multicolumn{6}{|c|}{ ИМТ } \\
\hline & \multicolumn{2}{|c|}{$\leq 24,9$} & \multicolumn{2}{|c|}{$25-29,9$} & \multicolumn{2}{|c|}{$30 \leq$} \\
\hline & Абс. & $\%$ & Абс. & $\%$ & Абс. & $\%$ \\
\hline $\mathrm{C} / \mathrm{C}$ & 2 & 28,6 & 4 & 57,1 & 1 & 14,3 \\
\hline $\mathrm{C} / \mathrm{G}$ & 7 & 58,3 & $\mathrm{O}$ & $\mathrm{O}$ & 5 & 41,7 \\
\hline $\mathrm{G} / \mathrm{G}$ & 1 & 4,2 & 2 & 8,3 & 21 & 87,5 \\
\hline
\end{tabular}


Больные БА с контролируемым течением, у которых была НМТ, все имели генотип $\mathrm{C} / \mathrm{C}$, а среди больных с избыточной массой тела $25 \%$ имели генотип $\mathrm{C} / \mathrm{C}$ и $75 \%$ - G/G. При наличии ожирения генотипы $\mathrm{C} / \mathrm{C}$ и $\mathrm{G} / \mathrm{G}$ выявлялись с одинаковой частотой (50 \%).

У пациентов с частично контролируемой БА при наличии НMT генотип C/C был у $20 \%, \mathrm{C} / \mathrm{G}$ - у $64 \%$, a G/G - у $16 \%$. При наличии избыточной массы тела генотип C/С был у $21,1 \%, \mathrm{C} / \mathrm{G}$ - у 47,4\%, a G/G - y 31,6 \%, а ожирения - у $14,3 \%, 31,4 \%$ и 54,3\% соответственно. Таким образом, высокая частота генотипа $\mathrm{G} / \mathrm{G}$ обнаружена у больных с избыточной массой тела и ожирением, что косвенно свидетельствует о связи аллеля $\mathrm{G}$ c ожирением.

Отсутствие контроля БА выявлено у 43 больных. Частота аллельных вариантов гена в зависимости от ИМТ у данных больных представлена в табл. 4. При отсутствии контроля и наличии НМТ частота аллельных вариантов гена составила: C/C - 20 \%, C/G - 70 \%, a G/G $10 \%$, при наличии избыточной массы тела: $\mathrm{C} / \mathrm{C}-66,7 \%, \mathrm{G} / \mathrm{G}-33,3 \%$, а при ожирении $3,7 \%, 18,5 \%$ и 77,8 \% соответственно. Таким образом, установлено высокую частоту G/G генотипов у больных БА с ожирением при отсутствии контроля течения заболевания.

Обсуждение результатов исследования. Наличие ожирения приводит к возникновению БА, утяжелению ее клинического течения и затруднения контроля заболевания в связи с развитием резистентности к базисной терапии [3, 4, 9]. Анализ популяционных данных свидетельствуют о низком контроле БА и большей вероятности тяжелого персистирующего течения заболевания при наличии ожирения, чем при НМТ [4, 7]. В целом, эти исследования показывают, что у пациентов с ожирением БА, как правило, хуже контролируется и тяжелее протекает.

Причины более тяжелого течения БА у лиц, страдающих ожирением, вероятно, являются многофакторными. Одним из факторов, который может способствовать плохому контролю БА, является отсутствие адекватного ответа на противоастматические препараты в силу генетических особенностей. Частично изучены однонуклеотидные полиморфизмы, связанные с риском неконтролируемой БА, снижением легочной функции и неполным ответом на медикаментозное лечение БА [11].

Проведенное нами исследование дополняет эти данные и демонстрирует взаимосвязь между контролем БА, однонуклеотидным BclI полиморфизмом гена ГР и ИМТ. Обнаружено, что частота G/G генотипа по BclI полиморфизму гена ГР у больных БА с ожирением и отсутствием контроля заболевания достоверно выше, что подтверждает вероятную роль данного генотипа, как в возникновении ожирения, так и в неконтролируемом течении заболевания.

\section{Выводы:}

1. Распределение генотипов $\mathrm{C} / \mathrm{C}, \mathrm{C} / \mathrm{G}$ и $\mathrm{G} / \mathrm{G}$ по Bcl1 полиморфизму гена ГР у больных БА с разным ИМТ показало статистически достоверную разницу и связь $\mathrm{G} / \mathrm{G}$ генотипа с ожирением.

2. Установлено достоверное отличие по распределению генотипов в зависимости от уровня контроля БА: при наличии контролируемой БА чаще встречался генотип С/С, при отсутствии контроля - генотип $\mathrm{G} / \mathrm{G}$.

3. Доказано ассоциацию между $\mathrm{G} / \mathrm{G}$ генотипом у больных БА с ожирением и отсутствием контроля течения заболевания.

\section{Примечания:}

1. Akerman M.J.H., Calacanis C.M., Madsen M.K. Relationship between asthma severity and obesity. J. Asthma 2004; 41(5): 521-526.

2. Boulet L.P. Asthma and obesity. Clin. Exper. Allergy 2013; 43(1): 8-21.

3. Boulet L.P., Franssen E. Influence of obesity on response to fluticasone with or without salmeterol in moderate asthma. Respir. Med. 2007; 101(11): 2240-2247. 340.

4. Dixon A. The treatment of asthma in obesity. Expert Rev. Respir. Med. 2012; 6(3): 331-

5. Ford E.S. The epidemiology of obesity and asthma. J. Allergy Clin. Immunology 2005; 115(5): 897-910. 
6. Kajbaf T.Z., Asar S., Alipoor M.R. Relationship between obesity and asthma symptoms among children in Ahvaz, Iran: a cross sectional study. Ital. J. Pediatrics 2011; 6: 37-41.

7. Mosen D.M., Schatz M., Magid D.J. et al. The relationship between obesity and asthma severity and control in adults. J. Allergy Clin. Immunol. 2008; 122(3): 507-511.

8. Pietras T., Panek M., Tworek D. et al. The BclI single nucleotide polymorphism of the human glucocorticoid receptor gene $\mathrm{h}-\mathrm{GR} / \mathrm{NR}_{3} \mathrm{C} 1$ promoter in patients with bronchial asthma: pilot study. Mol. Biol. Rep. 2011; 38(6): 3953-3958.

9. Saint-Pierre P., Bourdin A., Chanez P. et al. Are overweight asthmatics more difficult to control? Allergy 2006; 61(1): 79-84.

10. Sutherland E.R., Goleva E., Strand M. et al. Body mass and glucocorticoid response in asthma. Am. J. Respir. Crit. Care Med. 2008; 178: 682-687.

11. Tantisira K., Weiss S. The pharmacogenetics of asthma treatment. Curr. Allergy Asthma Rep. 2009; 9(1): 10-17.

12.Van Rossum E.F., Koper J.W., van den Beld A.W. et al. Identification of the BclI polymorphism in the glucocorticoid receptor gene: association with sensitivity to glucocorticoids in vivo and body mass index. Clin. Endocrinol. (Oxf). 2003; 59(5): 585-592.

13.Varraso R., Siroux V., Maccario J. et al. Asthma severity is associated with body mass index and early menarche in women. Amer. J. Respir. Crit. Care Med. 2005; 171(4): 334-339.

УДК 616.151.5 - 056. 7-07:618.3: 575.2

Уровень контроля бронхиальной астмы в зависимости от генотипа по BCL1
полиморфизу гена глюкокортикоидного рецептора и массы тела

${ }^{1}$ Владислава Владимировна Кмита

${ }^{2}$ Виктор Феликсович Орловский

3 Людмила Никодимовна Приступа

1-3 Сумский государственный университет, Украина

кафедра внутренней медицины последипломного образования

${ }^{1}$ E-mail: vlady_dytko@ukr.net

2 Доктор медицинских наук, профессор

E-mail:Simmed50@gmail.com

3 Доктор медицинских наук, профессор

E-mail: lyudmyla_prystupa@ukr.net

Аннотация. Изучено частоту генотипов по Bcl1 полиморфизму гена глюкокортикоидного рецептора (ГР) в зависимости от уровня контроля бронхиальной астмы (БА) и индекса массы тела (ИМТ), а также - взаимосвязь с этими показателями.

Обследовано 188 пациентов с БА и 95 практически здоровых лиц. Определение однонуклеотидного BclI полиморфизма гена ГР проводили методом полимеразной цепной реакции с последующим анализом длины рестрикционных фрагментов.

Проведенное нами исследование продемонстрировало взаимосвязь между контролем БА, BclI полиморфизмом гена ГР и ИМТ. Распределение генотипов C/C, C/G и G/G по Bcl1 полиморфизму у больных БА показало достоверную разницу между пациентами с разным ИМТ и связь G/G генотипа с ожирением. Показано достоверное отличие по распределению генотипов в зависимости от уровня контроля БА: при наличии контролируемой БА достоверно чаще встречался $\mathrm{C} / \mathrm{C}$ генотип, при отсутствии контроля $-\mathrm{G} / \mathrm{G}$ генотип. Таким образом, установлено, что частота G/G генотипа по BclI полиморфизму гена ГР у больных БА с ожирением и отсутствием контроля за течением заболевания достоверно выше, что подтверждает роль данного генотипа, как в возникновении ожирения, так и в отсутствии контроля заболевания. контроль.

Ключевые слова: бронхиальная астма; BclI полиморфизм; индекс массы тела; 